\title{
THEORETICAL BASIS FOR CALCULATION OF CHARGES FOR ACCESS TO RAILWAY INFRASTRUCTURE IN THE LIGHT OF EUROPEAN UNION LAW
}

\author{
JULIUSZ ENGELHARDT
}

University of Szczecin, POLAND

e-mail: juliusz.engalhardt@wzieu.pl

RECEIVED
ACCEPTED
JEL
CLASSIFICATION

KEYWORDS

ABSTRACT

\author{
27 November 2017 \\ 5 January 2018 \\ L98, N74, O18, R42, R48
}

rail infrastructure, charges, charges differentiating

This article discusses the rules for calculation of charges levied for access to railway infrastructure under the European Union directives and based on economic categories such as "marginal costs", "direct costs", "fixed costs", and "variable costs". The introductory part of the article refers to Directive $91 / 440$, historically the first legal act that referred to the issue of calculation of charges levied for access to railway infrastructure. Subsequently, the provisions of Directive 2001/14, adopted in the so-called "first railway package", and interpretative ambiguities in this regard were indicated. As a result, the European Commission had for several years promoted the idea that charges levied for access to railway infrastructure should be calculated on the basis of the theoretical category of "marginal cost", although no provision of the applicable directive indicated such category. Since the Member States did not accept this idea and used their own calculation systems, the European Commission gave rise to infringement proceedings before the Court of Justice of the European Union, accusing several Member States of infringing the provisions of Directive 2001/14, regarding the calculation of charges levied for access to railway infrastructure. Undoubtedly, the most important proceeding was the one against Poland, which concluded with the judgment delivered by the Court of Justice of the European Union of 30 May 2013. The final part of this article includes references to this judgment, as well as new provisions on the calculation of charges levied for access to railway infrastructure set forth in Directive 2012/34, and the implementing regulation 2015/909 issued on its basis.

\section{Introduction}

The rules for calculating charges levied for access to railway infrastructure in the European Union were set out for the first time in Directive 91/440 on the development of Community's railways adopted in July 1991 (Directive 91/440, 1991). Article 8 of this directive stipulated that "The manager of the infrastructure shall charge a fee for the use of the railway infrastructure for which he is responsible", and further "The user fee, which shall be calculated 
in such a way as to avoid any discrimination between railway undertakings, may in particular take into account the mileage, the composition of the train and any specific requirements in terms of such factors as speed, axle load and the degree or period of utilization of the infrastructure" (Directive 91/440, 1991).

Establishing the principle of use of railway infrastructure against payment in 1991 was one of the pillars of the new European Union policy in the railway sector, and was obviously connected with another pillar of this policy in the form of establishing the principle of separation of rail infrastructure management function from an operation function (transport operation) in railway undertakings. In order to facilitate the implementation of Directive 91/440 provisions, on 19 June 1995 the Council of the European Communities adopted, inter alia, Directive No. 95/19, which regarded the allocation of railway infrastructure potential and charging fees for infrastructure (Directive $95 / 19,1995)$. The provisions of this directive, however, did not introduce any new elements regarding the rules for calculating charges levied for access to railway infrastructure, when compared to Directive 91/440. There was still no precise definition of what cost categories should be included in the calculation of infrastructure access charges, and which should not. This was a significant drawback, because the Member States had, in fact, no indication, either theoretical or practical, as to what general principles to use for their own model of calculating charges for access to railway infrastructure.

\section{The charyes levied for access to infrastructure in the first pailway package}

Directive 95/19 was repealed by Directive 2001/14/EC of the European Parliament and of the Council of 26 February 2001 on the allocation of railway infrastructure capacity and the levying of charges for the use of railway infrastructure and safety certification, adopted under the so-called first railway package (Directive 2001/14, 2001). Article 7 (3) of that directive stipulated that "...the charges for the minimum access package and track access to service facilities shall be set at the cost that is directly incurred as a result of operating the train service" (Directive 2001/14). The implementation of this provision and retaining the principle that it is the Member States themselves that determine the specific tariff principles for charges, resulted in introduction of calculation systems for charges levied for access to railway infrastructure by individual countries in 2001-2012, without any other guidance and based on their own interpretations of the term of "cost that is directly incurred as a result of operating the train services".

However, it should be emphasized that the European Commission used its own interpretation of this term, which was far different from the interpretation introduced by many Member States. This led to spectacular proceedings before the Court of Justice of the European Union, which the European Commission brought in against Poland and several other countries in October 2010. The action before the Court of Justice against Poland (Judgment, 2013) was based on the European Commission's allegation that Poland did not implement the principle resulting from Directive 2001/14 according to which "the charges for the minimum access package and track access to service facilities shall be set at the cost that is directly incurred as a result of operating the train service" (Article 7(3)). According to the Commission, the quoted regulation referred to the term "marginal costs", which should be understood only as costs generated by actual train movements, and not the fixed costs which cover, in addition to the costs connected to fare, overhead costs for the operation of the infrastructure which must be borne even in the absence of train movements. During the proceeding, the Polish party argued that the Polish statutory provisions accurately reflect Directive 2001/14 provisions. On the other hand, the Commission's claim that "the directly incurred cost as a result of operating trains" is "marginal cost" was considered to be unfounded by the Polish side, which 
stressed that especially in the absence of the EU definition of the former concept, Member States have a certain level of freedom to determine what should be included in direct cost, as well as use it as base for the amount of charges levied for access to railway infrastructure.

Advocate General at the Court of Justice did not share the European Commission's position regarding the restrictive, in his opinion, view as to the equality of the category of "marginal costs" and "costs that are directly incurred as a result of operating the train services".

Advocate General at the Court of Justice also expressed the view that an attempt to provide the exact legal definition of this term in EU law is unnecessary, as it is a concept in the field of economic sciences, the use of which causes serious practical difficulties. He also acknowledged the correctness of Polish statutory provisions regarding the calculation of charges (The Act, 2007). However, the Advocate raised also a different argument. He questioned the definition of the base for calculating charges set out in the implementing rules for the Railway Act, which, as subservient legislation to the Act, was included in the Regulation of the Minister of Infrastructure ${ }^{1}$, and stated that rules lead to inclusion of costs, which manifestly cannot be considered to be directly incurred as a result of operating the train service, when determining the charge for the minimum access package and track access to service facilities. In particular, in the Advocate's view, the maintenance or traffic management costs, that were mentioned in the implementing provisions, may be considered to be only partially directly incurred as a result of operating the train service, because they include fixed costs which must be borne by the manager after a stretch of line on the rail network has been made available to traffic, even in the absence of train movements. However, the financial costs remain unrelated to the train service, whereas financing costs are completely absent. The Advocate General ended his position with stating that the Republic of Poland infringed the relevant provision of Directive 2001/14.

In the light of the available documentation of case C-512/10 against Poland, it seems that the Advocate General at the Court of Justice imprecisely understood the essence of the Polish system of calculation charges levied for access to railway infrastructure resulting from the Act on railway transport. This system can be defined as a result calculation system in which the basis of the access rate calculation was, indeed, the total costs of providing infrastructure access services by the manager of the publicly available infrastructure, from which the amount of the "substitute" budgetary grant, specifically the one financing a part of these costs, was deducted, and thus defining the so-called calculation costs, i.e. the part of costs which was later divided by operation work in order to determine the level of unit rates. The essence of the calculation system defined in the Polish Rail Transport Act, which was in force during the proceedings before the Court of Justice, is expressed in formula (1):

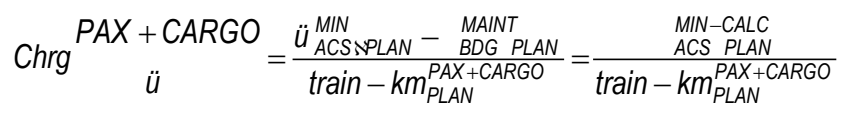

${ }^{1}$ Par. 8.1., Point 1-4 of the Ordinance of the Minister of Infrastructure of February 27, 2009 regarding the conditions of access and use of railway infrastructure (Decree, 2009), read as follows: „1. In calculating the rates for provision of the railway infrastructure, the infrastructure manager must take into consideration 1) direct costs, which cover a) maintenance costs, b) rail traffic management costs $\mathrm{c}$ ) amortisation; 2) the indirect costs of the activity, covering the reasonable expenses of the infrastructure manager other than the costs set out in point 1 and $3 ; 3$ ) financing costs relating to the repayment of loans taken out by the manager to develop and modernise the available infrastructure."

${ }^{2}$ It is worth noting here that Advocate General at the Court of Justice did not notice in the course of the proceeding the following provision of the then binding act on rail transport: "In setting the unit rates for the basic charge, the manager shall subtract from the amount earmarked for expenses for provision of the railway infrastructure to rail carriers the subsidy for the renovation and maintenance of the infrastructure from the budget of the State or of the local authorities and the resources provided from the Rail Fund." 
where:

$$
\begin{aligned}
& \mathrm{Chrg}_{A V G}^{P A X+C A R G O} \quad \text { - average charge for access to railway infrastructure, } \\
& C_{A C C-P L A N}^{\ddot{u}} \quad \text { - planned total costs of minimum access to railway infrastructure, } \\
& S_{B D G-P L A N}^{M A I N T} \quad \text { - planned budget subsidy for repairs and maintenance of railway infrastructure, } \\
& \text { train - } k m_{P L A N}^{P A X+C A R G O} \text { - planned operation work (length of routes planned to be sold) in train-kilometres, } \\
& C_{A C S-P L A N}^{M I N-C A C} \quad-\text { planned total calculation costs. }
\end{aligned}
$$

Based on the formula (1), it can be concluded that the cost category $C_{A C S-P L A N}^{M I N-C A L C}$, depending on the amount of the budget subsidy granted to the infrastructure manager in a given year $S_{B D G-P L A N}^{M A I N T}$, could express, in its economic terms, costs that were directly incurred as a result of operating the train services, i.e. the category defined in Directive 2001/14. However, the Advocate General did not investigate this problem at all.

The Court of Justice has eventually ruled that "by permitting the inclusion, in the calculation of charges levied for the minimum access package and track access to service facilities, of costs which cannot be regarded as costs directly incurred as a result of operating the train service, the Republic of Poland has failed to fulfil its obligations under Articles 7 (3) of Directive 2001/14/EC of the European Parliament and of the Council on the allocation of railway infrastructure capacity and the levying of charges for the use of railway infrastructure and safety certification, which was amended by Directive 2004/49/EC of the European Parliament and of the Council of 29 April 2004" (Judgment, 2013). It is also worth citing some guidelines for the construction of the calculation system of charges levied for access to the railway infrastructure that result from the Judgment. According to the Court of Justice (Judgment, 2013):

- The costs connected with signalling, traffic management, maintenance and repairs are liable to vary, at least partially, depending on traffic and, accordingly, may be considered, in part, to be directly incurred as a result of operating the train service.

- In the scope, in which they include fixed costs relating to the provision of a stretch of line on the rail network which the manager must bear even in the absence of train movements, the maintenance and traffic management costs regarding maintenance and rail traffic management... must be considered to be only partially directly incurred as a result of operating the train service.

- Indirect costs and financial costs... it is clear that they do not have a direct link with the operation of the train service.

- In the scope in which depreciation is determined, not on the basis of the actual wear of the infrastructure attributable to traffic, but with reference to accounting rules, it cannot be viewed as being directly incurred as a result of operating the train service.

In the light of the Judgment, the formula for calculating charges for access to railway infrastructure can be generally written down as follows:

$$
\operatorname{Chrg}_{A V G}^{\text {PAX }+C A R G O}=\frac{C_{D I R E C T-P L A N}^{\text {PART }}+D E P N_{D I R E C T}}{\text { train }-k m_{\text {CALC }}^{\text {PAX+CARGO }}}
$$


where:

$$
\begin{array}{ll}
C_{D I R E C T-P L A N}^{\text {PART }} & \text { costs related to signalling, traffic management, maintenance and repairs, which are } \\
& \text { partly incurred as a result of operating the train services, } \\
\text { DEPN } & \text { depreciation cost determined directly on the basis of the actual wear of the } \\
& \text { infrastructure attributable to traffic, } \\
\text { train }-k m_{\text {CALC }}^{\text {PAX }}- & \text { operational work in train-kilometres, included in the calculation of charges for access } \\
& \text { to the infrastructure. }
\end{array}
$$

It can be noticed that the general principle of the calculation system of charges levied for access to railway infrastructure, in the light of the Judgment, completely disregards the amount of budget subsidies granted to the infrastructure manager. Therefore, it should be recognized that the costs included in the charge calculation, their type and scope are a completely autonomous issue in relation to the budget subsidy for infrastructure maintenance. The last should be granted to the administrator based on separate rules, however EU law does not introduce stricter restrictions related to this issue, but instead indicates only that the Member State should conclude with the infrastructure manager agreements that cover the period of not less than three years and which provide for state financing. However, such agreements must include the so-called "incentives" to reduce the costs of providing infrastructure and the amount of access charges (Directive 2012/34/EU, 2012).

The Court of Justice, within the limits of their respective competences, dealt with the law and avoided taking a stand on the economics of infrastructure managers. Nevertheless, it could not completely move away from the economic problems. Although the Court rejected the category of "marginal costs" promoted by the European Commission as a base for charge calculations, it introduced into the legal system the economic category of "fixed costs", which are incurred as a result of operation of train services that cannot be included in the charge calculation, and "other costs" incurred as a result of operation of train services, which are to be the basis for calculating charges. Thus, indirectly, the Court pointed to the category of "variable costs"3 incurred as a result of operating the train services, which constitute a basis for calculation of charges levied for access to railway infrastructure. On the other hand, the fact that in economics the theoretical concept of "marginal cost", which is understood as the increase in the total cost of a production run for making one additional unit, is equivalent to a practical category appearing in enterprises in the form of a "variable cost per unit" of production is a completely different matter. It is therefore worth presenting a derivation that support this thesis.

In the classical economics, marginal cost $C_{M}$, with the index "1" of the actual value and the index "0" of the previous value, can be presented as follows:

where:

$$
C_{M}=\frac{\Delta C}{\Delta P}=\frac{C_{1}-C_{0}}{P_{1}-P_{0}}
$$

$\Delta C$ - increase of total production costs by unit,

$\Delta P$ - production increase by unit,

$C, P$ - with indexes 1 or 0 , respectively actual and previous value of costs and production.

${ }^{3}$ The obvious consequence of distinguishing the category of fixed costs in the judgment is that all other costs are variable costs. 
It should be noted that in the above calculation the denominator of formula (3) is always 1 , because:

$$
P_{1}-P_{0}=P_{0}+1-P_{0}=1
$$

and therefore, in further analysis, it can be omitted.

The total costs of formula (3) can be written analytically as follows:

$$
C=C_{V}^{T}+C_{F}^{T}=\left(C_{V}^{U} \times P\right)+C_{F}^{T}
$$

where:

$C_{V}^{T}$ - total variable costs,

$C_{F}^{T}$ - total fixed costs,

$C_{V}^{U}$ - variable unit cost.

By using the entered indexes of the actual and previous values, and omitting the formula denominator (3), which amounts to 1 , it is possible to express it in the following way:

$$
C_{M}=\left(C_{V 1}^{U} \times P_{1}\right)+C_{F 1}^{T}-\left(C_{V 0}^{U} \times P_{0}\right)-C_{F 0}^{T}
$$

Due to the short-term nature of the analysis, it is assumed that $C_{F 1}^{T}=C_{F 0}^{0}$, and therefore, after the reduction, the formula (6) has the form:

$$
C_{M}=\left(C_{V 1}^{U} \times P_{1}\right)-\left(C_{V 0}^{U} \times P_{0}\right)
$$

and then

$$
C_{M}=C_{V 1}^{U} \times\left(P_{0}+1\right)-\left(C_{V 0}^{U} \times P_{0}\right)
$$

it can be written that:

$$
C_{M}=C_{V 1}^{U}+\left(C_{V 1}^{U} \times P_{0}\right)-\left(C_{V 0}^{U} \times P_{0}\right)
$$

In accordance with the theory of economics, in the short-term analysis, it is assumed that the variable cost per unit is the same for each unit of production, ${ }^{4}$ i.e. it can be written that:

$$
C_{V 1}^{U}=C_{V 0}^{U}
$$

and therefore:

$$
C_{M}=C_{V 1}^{U}
$$

On the basis of the above derivation, it can be concluded that the theoretical category of "marginal cost" present in economics represents, in the practical terms of the functioning of enterprises, a value equivalent to "variable cost per unit" category analysed in a short period of time. Because the change in total costs in the short

\footnotetext{
${ }^{4}$ In economic theory, this kind of analysis is referred as a static analysis.
} 
term can only be caused by a change in the total variable costs, marginal costs can be defined as the increase of total variable costs by unit (Zalega, 2008).

Thanks to the (indirect) introduction of the principle of calculating charges levied for access to railway infrastructure based on the category of direct variable costs, incurred as a result of operating the train services, that, in fact, constitute marginal costs, it was possible to predict the appearance of some substantive difficulties when correctly implementing the new principles of calculating access charges to railway infrastructure, in accordance with the Judgment of the Court of Justice, not only in Poland, but also in other Member States, since the judgment shall apply in the entire European Union.

\section{Recast of the first railway package - Directive 2012/34}

At the time of the proceedings regarding the violation of the rules of the first railway package were filed by the European Commission against 12 Member States, including Poland for irregularities in the calculation system of charges levied for access to railway infrastructure, intensive work on the so-called modification of the first railway package were taking place. On November 21, 2012, the European Parliament and the Council adopted Directive 2012/34 on establishing a single European railway area (Directive 2012/34, 2012). In Article 31(3) of the Directive, an amended provision that regards the cost category on which the charges for access to railway infrastructure should be based, was included as follows: "...the charges for the minimum access package and for access to infrastructure connecting service facilities shall be set at the cost that is directly incurred as a result of operating the train service." In comparison to the analogous provision of Directive 2001/14, the change involved only the obligatory inclusion of charges for "access to infrastructure connecting service facilities" in the calculation systems, while the category "cost directly incurred as a result of operating the train service" remained unchanged. In view of this, it can be concluded that the adoption of Directive 2012/34 no longer had any relevance for the Luxembourg trial against Poland. On the other hand, of great importance was the Commission's announcement to include in the Directive the rules for calculating costs that are directly incurred as a result of operating the train service, before 16 June 2015. This meant setting a deadline by which the European Commission undertook to define more precisely the uniformly system for calculation charges for access to railway infrastructure, which would bind all Member States.

\section{Implementing regulation 2015/909}

The new European Commission Regulation was issued on the basis of the legislative deputation included in Directive 2012/34 ("amendment" to the first railway package). In this legal act, the Commission should have precisely defined the concept of "costs that are incurred directly as a result of operating the train services". The regulation was adopted and is binding in its entirety, as well as it has been directly applicable since 1 August 2015 in all Member States (Commission, 2015). Moreover, the Commission noted in the preamble that the Court of Justice has handed down the judgment on the calculation of direct costs incurred in operating the train services and that the regulation takes that judgment into account (Commission, 2015).

However, the above-mentioned regulation disappoints with the adopted method for defining charges levied for access to railway infrastructure, which are the most important element in the applicable calculation system. Similarly to Directive 2012/34, the regulation states that, firstly, "direct cost" means cost that is directly incurred as a result of the operation of train services and, secondly, that "direct costs on a network-wide basis shall be calculated as the difference between, on the one hand, the costs for providing the services of the minimum access 
package and for the access to the infrastructure connecting service facilities and, on the other hand, the non-eligible costs" (Commission, 2015). On the other hand, the non-eligible costs is a list, which includes the term "in particular", i.e. is non-exhaustive, of dozens of items ineligible for direct costs, including the item "fixed costs relating to the provision of a stretch of line which the infrastructure manager must bear even in the absence of train movement" (Commission, 2015). In this way, the quoted regulation regarding costs, which are incurred directly as a result of operating the train services and which are the foundation of the entire charge calculation system, does not provide a definite resolution, still leaving the Member States a large margin of their own interpretation possibilities, but also putting them at risk of possible litigation in the future.

It seems that the big paradox in the entire case described above is the fact that, on the one hand, the Court in its judgment against Poland questioned the so-called resultant determination of direct costs incurred as a result of the operation of train services (total costs of infrastructure manager minus the budget subsidy used to cover costs, other than direct costs) and did not even mention that such a fact occurred in Poland while examining the Commission's complaint. On the other hand, in 2015, the Commission introduced an implementing regulation, in which "direct costs incurred as a result of operation of the train services" are calculated using the output method (total costs of the railway infrastructure manager minus the non-eligible costs, i.e. costs to be covered and thus financed from budget subsidy). It can, of course, be claimed that the Polish system required the inclusion of the subsidy amount in this calculation, i.e., an element undoubtedly related to the transport policy, and that the system defined in Commission Implementing Regulation 2015/909 requires the inclusion of exhaustively listed cost items as costs to be covered by subsidies, i.e. it is potentially better, more precise, appropriate, and in line with EU law. This, however, does not change the fact that the system is resultant and was previously questioned by the Court.

\section{Summary}

The matter of determining the correct cost category that forms the basis for calculating charges levied for access to railway infrastructure has been for many years (since 1991) subject to controversies and debates in all European Union Member States. The provisions of subsequent EU directives 91/440, 2001/14, 2012/34, which referred to this issue, were too general and therefore imprecise. For several years, the European Commission has "promoted" the idea that charges for access to railway infrastructure should be calculated on the basis of the theoretical category of "marginal cost", although no provision of the applicable directive indicated such category. The Court of Justice of the European Union, in the proceedings against Poland, did not share the position of the European Commission in this matter. However, the Court introduced to the legal system the economic category of "fixed costs" incurred as a result of the operation of train services, which cannot be included in the charge calculation, and "other costs" incurred as a result of operation of the train services, which are to be the basis for charge calculations. Thus, the Court indirectly pointed to the category of "variable costs", incurred as a result of operating the train services, as a basis for calculation of charges levied for access to railway infrastructure. Nevertheless, this approach also does not seem appropriate, since the analysis presented in the article showed that the theoretical category of "marginal cost" is synonymous with the theoretical and practical category of "variable cost". The problem of the cost category, on which the calculation of charges levied for access to railway infrastructure is to be based in the European Union, has been pragmatically and partially solved by the European Commission that issued Implementing Regulation 2015/909 of 12 June 2015 on the modalities for the calculation of the cost that is directly incurred as a result of operating the train service, discussed in a general way in the article. However, this regulation regarding costs that 
are incurred directly as a result of operating the train service, and which are the foundation of the entire charge calculation system, does not provide a definite resolution, still leaving the Member States a large margin of their own interpretation of these provisions, but also putting them at risk of possible dispute proceedings in the future.

\section{References}

Commission Implementing Regulation (EU) 2015/909 of 12 June 2015 on the modalities for the calculation of the cost that is directly incurred as a result of operating the train service - the Official Journal of the European Communities of 2015, L 148/17.

Decree of the Ministry of Finance of 27 February 2009 on the conditions of access and use of railway infrastructure - (Journal of Laws of 2009, No 35, Item 274).

Directive 2001/14 of 26 February 2001 on the allocation of railway infrastructure capacity and the levying of charges for the use of railway infrastructure and safety certification - the Official Journal of the European Communities of 2001, L 75/29.

Directive 2012/34/EU of the European Parliament and of the Council of 21 November 2012 establishing a single European railway - the Official Journal of the European Communities of 2012, L 343/32.

Directive $91 / 440$ of the Council of the European Communities on the development of the Community's railways of 29 July 1991 - the Official Journal of the European Communities of $1991 \mathrm{~L} 237 / 25$.

Directive $95 / 19$ of the Council of the European Communities on the allocation of railway infrastructure capacity and the charging of infrastructure fees - the Official Journal of the European Communities of 1995, L 143/75.

Judgment of the Court of Justice of the European Union in Case C - 512/10 of 30 May 2013 - the Official Journal of the European Union, C 225/03.

The Act of 28 March 2003 on Railway Transport - Journal of Laws of 2007 No 16, item 94, as amended.

Zalega, T. (2008). Mikroekonomia. Warszawa Wydawnictwo Naukowe Wydziału Zarządzania Uniwersytetu Warszawskiego.

Cite this article aS: Engelhardt, J. (2018). Theoretical basis for calculation of charges for access to railway infrastructure in the light of European Union law. European Journal of Service Management, 1 (25), 81-89. DOI: 10.18276/ejsm.2018.25-10. 